\title{
O uso do cineclubismo para a abordagem da história local
}

\author{
Géssica Rocha da Silva \\ Universidade Estadual do Ceará ${ }^{1}$ \\ Raquel Sales Miranda \\ Universidade Federal do Cearáa
}

\begin{abstract}
Resumo: O ensino de história muitas vezes é baseado na memorização e não no processo de aprendizagem significativa do acontecimento histórico em seu contexto cultural e social. Nesse sentido, este trabalho tem como objetivo principal apresentar uma proposta de projeto educativo focado no uso do cineclubismo como alternativa para abordar a história local de forma mais contextualizada. A proposta aqui apresentada é baseada nos conteúdos da Base Nacional Comum Curricular (BNCC), para o ensino de história no $3^{\circ}$ ano dos Anos Iniciais do Ensino Fundamental (AIEF). O projeto foi idealizado durante a disciplina de Estágio no curso de Pedagogia (UECE), para ser aplicado com educandos do terceiro ano dos AIEF de uma escola pública de MaranguapeCE. Dessa forma, espera-se que esse projeto possa ser replicado por professores de História de diversas localidades, de forma a contribuir para a valorização da cultura cinematográfica e do ensino de história contextualizado.
\end{abstract}

Palavras-chave: Cineclubismo; História local; Ensino fundamental.

\section{The use of cineclubism for the approach of local history}

\begin{abstract}
History teaching is often based on memorization and not on the process of meaningful learning of the bistorical event in its cultural and social context. In this sense, this work has as main objective to present an educational project proposal focused on the use of cineclubism as an alternative to approach local history in a more contextualized way. The proposal presented here is based on the contents of the National Common Curriculum Base (BNCC), for the teaching of history in the 3rd year of the Initial Years of Elementary School (AIEF). The project was conceived during the internship course in pedagogy course (UECE), to be applied with third-year students of the AIEFs of a public school in Maranguape-CE. Thus, it is expected that this project can be replicated by history teachers from various locations, in order to contribute to the valorization of film culture and contextualized history teaching.
\end{abstract}

Keywords: Scientific literacy; Local history; Elementary school.

\footnotetext{
1 Graduada em Licenciatura em Pedagogia pela Universidade Estadual do Ceará. ORCID: https://orcid.org/0000-0002-0206-2163. E-mail: gessica.rocha@aluno.uece.br.

${ }^{2}$ Doutoranda do Programa de Pós-Graduação em Educação da Universidade Federal do Ceará. ORCID: https://orcid.org/0000-0003-3889-3185. E-mail: raquelsales@alu.ufc.br.
}

Cadernos GPOSSHE On-line, Fortaleza, v. 5, n. 1, 2021

https://revistas.uece.br/index.php/CadernosdoGPOSSHE

DOI: $10.33241 /$ cadernosdogposshe.v5i1

ISSN: $2595-7880$ 


\section{INTRODUÇÃO}

A escolha pela elaboração de um projeto voltado para o ensino de história se deve prioritariamente, ao fato da autora principal ter vivenciado nos anos iniciais do ensino básico os efeitos de um ensino de História pouco enriquecedor em relação ao reconhecimento histórico local, haja vista, as poucas informações existentes a respeito das raízes culturais e étnicas que constituem a identidade dos habitantes de Maranguape-CE. Havia uma carência de atividades que instigassem nos alunos a curiosidade investigativa para conhecer a história do seu próprio povo e cidade e, assim entender os reflexos do passado nas relações socioculturais.

O ensino de história tem gerado grandes reflexões acerca de sua abordagem pedagógica, já que se tornou muito difundida uma metodologia baseada na memorização e não no processo de aprendizagem significativa que seja focado no entendimento do acontecimento histórico, no contexto cultural e social e na forma como esse evento repercute no nosso presente, impactando em nossos pensamentos, comportamentos e ideologias.

Percebe-se que há espaços para serem preenchidos, repensados e inovados na prática pedagógica do ensino de história que deve ir além de instrumentos institucionalizados, ultrapassando as fronteiras das escolas e explorando histórias locais e cotidianas, fundamentando-se nesse novo fazer didático da história, pois essa abordagem acarretará em diversos saberes e na solidificação da aprendizagem dos educandos.

Dessa forma, entendemos que pensar na história, é nos permitir analisar o passado e suas contribuições para o presente. De acordo com Caimi e Rocha (2014), o debate corrente entre intelectuais no tocante ao sentido da história, integrado às narrativas da História Universale da História Geral repercutem os movimentos revolucionários e transformações em direção ao conceito da história que deveria fomentar a formação cidadã.

Quando nascemos já carregamos conosco uma história influenciada por outras pessoas, então começamos a acolher as influências culturais, sociais, étnicas e morais. Estes aspectos fomentam a escrita das primeiras páginas de nossa história e a construção de nossa identidade. 
O ensino da história nos Anos Iniciais do Ensino Fundamental (AIEF), promove o reconhecimento histórico, pessoal e local de onde os educandos residem. Dessa forma, de acordo com os Parâmetros Curriculares Nacionais (PCNs) há a preocupação com os estudos da história local, a partir da necessidade dos alunos expandirem sua capacidade de observar, investigar e descobrir a história do seu entorno, para assim compreender as relações sociais eeconômicas existentes no seu próprio tempo e reconhecer a presença de outros contextos em seu cotidiano (BRASIL, 1997).

Apesar dos PCN representarem uma contribuição importante para o ensino de história, atualmente o planejamento dessa disciplina é baseado na Base Nacional Comum Curricular (BNCC), por isso a proposta que será apresentada neste artigo se baseia nas orientações presentes nesse último documento.

Dessa forma, o objetivo deste artigo é apresentar o projeto 'Cineclubismo na História' como alternativa para abordar a história local. A proposta aqui apresentada é baseada nos conteúdos propostos na BNCC, para o ensino de história no $3^{\circ}$ ano do Ensino Fundamental.

De acordo com a BNCC, a área de conhecimento contemplada nesse projeto é a de ciências humanas e o componente curricular é a disciplina de história. Já a unidade temática é: 'o lugar em que vive', objetivando identificar os marcos históricos do lugar em que os estudantes estão inseridos e compreender seus significados, respaldados nos registros de memória da cidade (nomes de ruas, monumentos, edifícios, dentre outros), e nos critérios que explicam a escolha desses nomes (BRASIL, 2017).

De acordo com Santos (2020), o cineclubismo se caracteriza como um movimento que faz parte da história do cinema enquanto arte e linguagem. Dessa forma, essa estratégia pode ser utilizada para a exposição de elementos históricos, sociais e culturais dos municípios, a partir da apresentação de documentários acerca dos sujeitos que fizeram parte da história dessa população e que hoje nomeiam praças, museus e escolas como uma forma de homenagear e representar o seu legado para a população.

Vale ressaltar que os materiais utilizados no cineclubismo são de fácil acesso, como: mesa, notebook e projetor. E no caso das aulas remotas, podem ser disponibilizados links 
de vídeos para os estudantes assistirem em casa ou podem ser exibidos trechos de filmes durante aulas pela ferramenta digital Google Meet.

\section{METODOLOGIA}

Este trabalho é considerado uma pesquisa de abordagem qualitativa que, segundo Minayo (2015) é uma abordagem que permite compreender de forma mais aprofundada as temáticas das pesquisas da área social.

Vale destacar que este projeto foi elaborado como uma proposta para a disciplina de Estágio no Ensino Fundamental I do curso semipresencial de Pedagogia da Universidade Estadual do Ceará (UECE).

Devido ao momento pandêmico que acometeu mundialmente todas as pessoas e o funcionamento dos mais variados setores econômicos e institucionais, as escolas e as universidades também tiveram as suas atividades presenciais suspensas por tempo indeterminado. Dessa forma, visando a continuidade da disciplina de Estágio, foi proposta a elaboração de projetos que poderiam ser aplicados posteriormente nas escolas. $O$ direcionamento da implantação deste projeto nas escolas públicas da cidade de Maranguape/CE, foi devido ao fato da referida cidade ser o polo que oferece assistências de infraestrutura e recursos para que aconteçam as aulas presenciais do curso de pedagogia.

Assim, este artigo se constitui como uma forma de divulgar um projeto que pode ser adaptado e aplicado em diversos contextos, como possibilidade metodológica para a abordagem da história local. Agrega-se na proposta da criação deste projeto a inovação e criação de estratégias para ajudar na formação docente, uma vez que o estágio supervisionado propicia as investigações e observações de estratégias pedagógicas que levem a uma identificação com o papel atuante de um educador, surgindo durante a atuação em sala de aula um agir pedagógico crítico, social, cultural e humano. Estas ações devem ser frequentes no trabalho docente enquanto função cidadã e pertencente a instituição de ensino.

\footnotetext{
${ }^{3}$ Uma ferramenta que promove videoconferência com o objetivo de facilitar a participação em reuniões.
} 
O projeto cineclubismo na história, foi idealizado para ser aplicado com educandos do terceiro ano dos AIEF de uma escola pública, que está localizada na área central do municípiode Maranguape-CE, partindo do pressuposto de que um projeto persiste no conhecimento e pesquisa de uma problemática ou assunto direcionado a entender as necessidades educacionais dos alunos, instigando, estimulando e fomentando o experimentar das descobertas sobre as suas raízes históricas.

Percebe-se que provavelmente, o público alvo possui uma carência no aspecto cultural, visto que a cidade de Maranguape-CE não incorpora em sua realidade uma aquisição cultural que permita a todos adentrarem nesse universo da erudição, principalmente no que se refere ao acesso livre ao cinema. Rego (1995, p.41) tendo como referência os estudos de Vygotsky se debruça sobre a importância de um meio social e cultural rico para o processo de aprendizagem:

A primeira se refere à relação indivíduo/sociedade. Vygotsky afirma que as características tipicamente humanas não estão presentes desde o nascimento do indivíduo, nem são mero resultado das pressões do meio externo. Elas resultam da interação dialética do homem e seu meio sócio-cultural. Ao mesmo tempo em que o ser: humano transforma o seu meio para atender suas necessidades básicas, transforma-se a si mesmo.

Vale ressaltar que os educandos tidos como público-alvo deste projeto se incluem nas concepções das funções psicológicas superiores, pautadas nas etapas do desenvolvimento da memória voluntária; atenção consciente; imaginação criativa; linguagem; pensamento conceitual; percepção mediada; desenvolvimento da vontade e raciocínio lógico.

Assinalando o que foi exposto por Lucci (2006, p.7):

A teoria histórico-cultural ou sociocultural do psiquismo humano de Vygotsky, também conhecida como abordagem sociointeracionista, toma como ponto de partida as funções psicológicas dos indivíduos, as quais classificou de elementares e superiores, para explicar o objeto de estudo da sua psicologia: a consciência.

Diante dessa afirmação, o projeto que será aqui apresentado, tem como objetivo geral ajudar na mediação do aprendizado dos marcos históricos do lugar em que os alunos 
estão inseridos e compreender seus significados, tendo como referência os registros de memória da cidade de Maranguape-CE.

Já os objetivos específicos do projeto são: 1. Abordar a história local a partir da identificação de marcos históricos (como nomes de ruas, monumentos, dentre outros); 2. Compreender o significado e a relevância desses marcos históricos; 3. Apresentar documentários que abordam personagens históricos de Maranguape-CE e; 4. Estimular a escrita crítico reflexiva, indicando a evolução da aprendizagem após o cineclubismo.

\section{RESULTADOS E DISCUSSÃO}

Analisando o Índice de Desenvolvimento Municipal (IDM), de Maranguape-CE, que contempla os indicadores de educação (taxa de alfabetização de pessoas acima de 15 anos de idade e a taxa bruta de frequência à escola); longevidade (esperança de vida ao nascer) e renda(Produto Interno Bruto-PIB per capita), percebemos que o município se encontra em estado de desenvolvimento instável, expressando o aumento no PIB per capita de 2006 para 2008 e diminuindo de 2008 para 2009, com apenas 9,35\% de aumento no período total (PREFEITURAMUNICIPAL DE MARANGUAPE, 2015).

Quanto ao IDM, consta-se no Plano Municipal de Educação (PME), indicadores quantitativos que apontam que Maranguape ocupava no ano de 2010 o $27^{\circ}$ lugar (PREFEITURA MUNICIPAL DE MARANGUAPE, 2015). Estes resultados demonstram um déficit na educação, o que aponta a necessidade de replanejamento e de medidas pedagógicas eficazes a fim de que a educação do município venha a atender aos critérios de qualidade, assim estabelecendo estratégia de políticas educacionais para garantir o menor índice de evasão escolar.

Dessa forma, o desenvolvimento dessa proposta de projeto pode contribuir para uma educação mais contextualizada, o que futuramente, se for replicado em várias escolas, pode contribuir para a melhoria dos índices educacionais do município de Maranguape. Compreende-se que introduzir a essência cinematográfica na escola introduz o aluno no universo da cultura, mas não uma cultura desconhecida, e sim, uma pertencente a realidade do público participante. Ajudando os alunos a obterem a aquisição da compreensão e 
protagonismo na sociedade que fazem parte, pois como foi exposto é um recurso rico para auxiliar a instituição de ensino a explorar a cultura dos educandos em sua maximização.

Para a utilização do cineclubismo na educação, é necessário um planejamento espacial, visando um espaço estimulante para o aprendizado. Percebe-se que quando se é planejada a organização do ambiente, buscando trazer uma harmonização do clima cinematográfico, podemos oportunizar uma atividade dinâmica que se distancie do tradicionalismo, ajudando na assimilação satisfatória dos objetivos geral e específicos do projeto, potencializando o desenvolvimento de habilidades e competências.

Trabalhar o cinema na sala de aula pretendendo explorar com o aluno este outro universo de conhecimento e emoções que pode expandir sua capacidade de percepção e compreensão do mundo em que vive, consiste, no entanto, em garantir que a avaliação no tocante a percepção da história produzida se efetivou e tomou a proporção almejada. Para concretizar os objetivos, competências e habilidades pontuadas no projeto é preciso a construção do plano das ações pedagógicas que discorra e organize o processo de execução.

Dessa forma, no Quadro 1, está apresentada a organização do projeto em atividades baseadas em diferentes estratégias. Vale ressaltar que as primeiras atividades são preparatórias para a utilização do cineclubismo e por isso se baseiam em diversas atividades artísticas como o teatro e a música.

\begin{tabular}{|c|c|c|c|}
\hline Temática & Objetivo & $\begin{array}{c}\text { Estratégia Metodológica e } \\
\text { Recursos }\end{array}$ & Avaliação \\
\hline $\begin{array}{l}\text { Como se } \\
\text { constrói a } \\
\text { história? }\end{array}$ & $\begin{array}{lr}\text { Construir através } \\
\text { de suas vivências } \\
\text { e experiências o } \\
\text { conceito de } \\
\text { história, e sua } \\
\text { importância para } \\
\text { a compreensão } \\
\text { histórica da } \\
\text { sociedade. }\end{array}$ & $\begin{array}{l}\text { Inicialmente haverá um diálogo em } \\
\text { grupo, onde buscaremos levantar o } \\
\text { conhecimento prévio e a opinião dos } \\
\text { estudantes sobre o conceito de } \\
\text { história, por meio de } \\
\text { questionamentos. Após esse debate } \\
\text { inicial, faremos uma apresentação } \\
\text { com o uso de fantoche para a } \\
\text { fundamentação do aprendizado } \\
\text { construído coletivamente. } \\
\text { Recursos: Mesa, Fantoches, Lençol }\end{array}$ & $\begin{array}{l}\text { Avaliação no } \\
\text { segmento } \\
\text { grupal, onde } \\
\text { será } \\
\text { observado se } \\
\text { os alunos já } \\
\text { tem uma } \\
\text { noção de } \\
\text { comoacontece } \\
\text { o estudo da } \\
\text { história } \\
\text { baseados em } \\
\text { suas } \\
\text { experiências } \\
\text { pessoais, nos } \\
\text { lugares }\end{array}$ \\
\hline
\end{tabular}




\begin{tabular}{|c|c|c|c|}
\hline & & & $\begin{array}{l}\text { frequentados } \\
\text { por eles e na } \\
\text { conjuntura } \\
\text { municipal. }\end{array}$ \\
\hline $\begin{array}{l}\text { Cantarolando o } \\
\text { hino de } \\
\text { Maranguape }\end{array}$ & $\begin{array}{l}\text { Reconhecer e } \\
\text { refletir sobre o } \\
\text { hino municipal } \\
\text { como registro } \\
\text { cultural, } \\
\text { representativo } \\
\text { da contação das } \\
\text { histórias sociais } \\
\text { e étnicas } \\
\text { formuladoras } \\
\text { das raízes da } \\
\text { população } \\
\text { maranguapense. }\end{array}$ & $\begin{array}{l}\text { Iniciaremos com uma roda de } \\
\text { conversa referente ao conhecimento } \\
\text { dos alunos sobre o hino de } \\
\text { Maranguape. Perguntando se os } \\
\text { mesmos se já escutaram esta canção e } \\
\text { sua compreensão sobre a história } \\
\text { representada. Diante da proposta, } \\
\text { reproduziremos um vídeo do hino que } \\
\text { é permeado por várias imagens do } \\
\text { Município de Maranguape e o seu } \\
\text { povo } \\
\text { (https://www.youtube.com/watch?v } \\
\text { =CnmpFdg8S EY). Após isso, será } \\
\text { realizado um jogo denominado como: } \\
\text { encaixe o verso. Escreveremos no } \\
\text { quadro a letra do hino deixando } \\
\text { espaços para que os educandos } \\
\text { possam ir preenchendo conforme o } \\
\text { andamento da dinâmica. Uma caixa } \\
\text { ficará exposta para retirarem um verso } \\
\text { de cada vez e coletivamente indicarem } \\
\text { em qual espaço deverá ser encaixado. } \\
\text { Recursos: Caixa de papelão, Papel } \\
\text { oficio, Fita gomada, Caixa de som, } \\
\text { Notebook, Projetor de slides. }\end{array}$ & $\begin{array}{l}\text { Avaliação } \\
\text { pautada na } \\
\text { observação se } \\
\text { os educandos } \\
\text { conseguiram } \\
\text { identificar o } \\
\text { hino de } \\
\text { Maranguape- } \\
\text { CE como um } \\
\text { documento } \\
\text { cultural e } \\
\text { descritivo da } \\
\text { construção } \\
\text { étnica } \\
\text { cultural. }\end{array}$ \\
\hline $\begin{array}{l}\text { Composição de } \\
\text { nossa etnia }\end{array}$ & 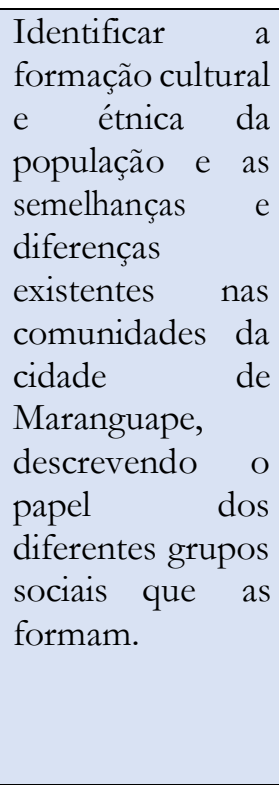 & $\begin{array}{l}\text { Em um diálogo em grupo } \\
\text { estimularemos os estudantes a } \\
\text { buscarem em suas lembranças os } \\
\text { povos citados na letra do hino de } \\
\text { Maranguape. Pediremos que } \\
\text { descrevam as características físicas dos } \\
\text { colegas, fortalecendo a } \\
\text { ideia da heterogeneidade, desse } \\
\text { modo, indagando aos alunos como } \\
\text { eles imaginam ser as características } \\
\text { dos povos que proporcionaram essa } \\
\text { composição étnica. Assim, dando } \\
\text { prosseguimento a história da } \\
\text { construção de Maranguape, } \\
\text { reproduziremos um vídeo que } \\
\text { representa um momento cultural na } \\
\text { cidade de Maranguape, que é o } 07 \\
\text { de setembro }\end{array}$ & $\begin{array}{l}\text { Constatar se } \\
\text { os alunos } \\
\text { conseguiram } \\
\text { identificar a } \\
\text { formação } \\
\text { étnica e } \\
\text { cultural e as } \\
\text { semelhanças e } \\
\text { diferenças } \\
\text { entre os povos } \\
\text { que compõem } \\
\text { a sua } \\
\text { descendência, } \\
\text { bem como a } \\
\text { assimilação } \\
\text { dos papeis } \\
\text { executados } \\
\text { pelos }\end{array}$ \\
\hline
\end{tabular}




\begin{tabular}{|c|c|c|c|}
\hline & & $\begin{array}{l}\text { (https://www.youtube.com/watch?v } \\
=Z-\text { qfvzaKbbw). Desse modo os } \\
\text { educandos poderão perceber as } \\
\text { diferentes composições éticas da } \\
\text { população maranguapense. } \\
\text { Recursos: Caixa de som, Notebook, } \\
\text { Projetor deslides. }\end{array}$ & $\begin{array}{l}\text { diferentes } \\
\text { grupos } \\
\text { étnicos. }\end{array}$ \\
\hline $\begin{array}{l}\text { Documentário } \\
\text { conceitual sobre } \\
\text { a construção da } \\
\text { história } \\
\text { englobando as } \\
\text { histórias dos } \\
\text { alunos }\end{array}$ & $\begin{array}{l}\text { Identificar a } \\
\text { construção da } \\
\text { História na } \\
\text { perspectiva da } \\
\text { sua formação } \\
\text { enquanto } \\
\text { sujeito e } \\
\text { compreender os } \\
\text { espelhamentos } \\
\text { de outras } \\
\text { histórias em suas } \\
\text { vidas e os } \\
\text { significados } \\
\text { histórico, social, } \\
\text { cultural e étnico, } \\
\text { considerando a } \\
\text { linguagem do } \\
\text { cinema como } \\
\text { uma ferramenta } \\
\text { crítica e e } \\
\text { reflexiva. }\end{array}$ & $\begin{array}{l}\text { Haverá uma amostra da gravação em } \\
\text { formato de documentário das } \\
\text { atividades que até então foram } \\
\text { desenvolvidas com os educandos, já } \\
\text { que o debate sobre como acontece a } \\
\text { construção da história, sobre a análise } \\
\text { do hino de Maranguape e a } \\
\text { composição étnica gera um material } \\
\text { audiovisual rico para o entendimento } \\
\text { da história dos maranguapenses. } \\
\text { Assim, os alunos se apropriarão dos } \\
\text { aprendizados e seus significados, por } \\
\text { intermédio da arte atrelada ao cinema. } \\
\text { Recursos: Mesa, Projetor, Notebook }\end{array}$ & $\begin{array}{ll}\text { Perceber } & \text { se } \\
\text { os estudantes } \\
\text { conseguiram } \\
\text { identificar } & \text { os } \\
\text { reflexos } & \text { da } \\
\text { história } & \text { na } \\
\text { relação } & \text { de } \\
\text { construção do } & \text { sujeito } \\
\text { histórico. } & \end{array}$ \\
\hline $\begin{array}{lr}\text { Explorando a } & \text { a } \\
\text { história } & \text { do } \\
\text { município } & \end{array}$ & $\begin{array}{l}\text { Identificar os } \\
\text { marcos } \\
\text { históricos do } \\
\text { lugar em que } \\
\text { estão inseridos e } \\
\text { compreender } \\
\text { seus } \\
\text { significados } \\
\text { históricos, } \\
\text { sociais, culturais } \\
\text { e étnicos, } \\
\text { considerando a } \\
\text { linguagem } \\
\text { cinema como } \\
\text { uma ferramenta } \\
\text { crítica e } \\
\text { reflexiva. }\end{array}$ & $\begin{array}{l}\text { Dando início a conversa em grupo, } \\
\text { discutiremos sobre os lugares do } \\
\text { município de Maranguape mais } \\
\text { frequentados e conhecidos pelos } \\
\text { alunos (praças, museus, pousadas e } \\
\text { etc.), questionando se os mesmos } \\
\text { sabem a história daquele lugar, o } \\
\text { porquê do nome e sua contribuição } \\
\text { para a população maranguapense. } \\
\text { Diante do compartilhamento de } \\
\text { informações e conhecimentos, } \\
\text { utilizaremos a linguagem } \\
\text { cinematográfica por intermédio do } \\
\text { momento 'Cineclubismo na } \\
\text { com a proposta, reproduziremos os } \\
\text { vídeos que contam a história de vida } \\
\text { de ChicoAnysio e } \\
\text { Capistrano de Abreu: }\end{array}$ & $\begin{array}{l}\text { Perceber se há } \\
\text { aapreensão do } \\
\text { conhecimento } \\
\text { da história } \\
\text { local e o } \\
\text { desenvolvime } \\
\text { nto da } \\
\text { habilidade de } \\
\text { observar, } \\
\text { investigar e } \\
\text { descobrir a } \\
\text { história } \\
\text { incorporada } \\
\text { em seu } \\
\text { entorno, } \\
\text { formulando o } \\
\text { entendimento } \\
\text { das relações } \\
\text { sociais e }\end{array}$ \\
\hline
\end{tabular}




\begin{tabular}{|l|l|l|}
\hline & $\begin{array}{l}\text { https://www.youtube.com/watch?a } \\
\mathrm{pp}=\text { desktop\& v=KE4AbHtwSMQ; } \\
\text { https://youtu.be/vXGU7mU7Oic). }\end{array}$ & $\begin{array}{l}\text { econômicas } \\
\text { existentes no } \\
\text { seu próprio } \\
\text { tempo e a } \\
\text { Vale lembrar que Chico Anysio tem } \\
\text { sua representação e contribuição no } \\
\text { museu construído recentemente no } \\
\text { município e Capistrano de Abreu é } \\
\text { identificação } \\
\text { da presença de } \\
\text { outros tempos } \\
\text { homenageado na nomeação da praça } \\
\text { mais movimentada do centro da dia- a- } \\
\text { dia. } \\
\text { cidade. A sala terá sua organização de } \\
\text { modo a transparecer o clima } \\
\text { cinematográfico. } \\
\text { Recursos: Mesa, Projetor, Notebook. }\end{array}$ \\
\hline
\end{tabular}

Quadro 1- Organização do projeto Cineclubismo e História local

Fonte: As autoras.

Com a proposição desse projeto, o cinema é apresentado como uma linguagem artística relevante para o aprendizado de crianças, promovendo a capacidade crítica, analítica e investigativa de entender o fazer histórico.

Com base nas observações realizadas durante um dos estágios no curso de Pedagogia, percebemos a necessidade da inserção de filmes na atuação pedagógica, pois comumente presenciamos sempre comentários entre os educandos acerca das cenas dos filmes que assistiram na casa de um amigo ou com os pais. Esses relatos indicam um forte apreço pelo mundo cinematográfico, pois os estudantes transbordam empolgação, imaginação e argumentos para representar seu entendimento a respeito do comportamento de um personagem ou sobre uma determinada cena.

Todos esses aspectos tornam este projeto um eficiente recurso metodológico para ajudar os estudantes a desenvolverem competências e habilidades propostas na Base Nacional ComumCurricular (BNCC) e nos Parâmetros Curriculares Nacionais (PCNs). Dessa forma, esperamos através deste projeto despertar nos educandos um novo olhar e descobertas sobre a construçãoda identidade cultural, social e étnica do município de Maranguape, cidade onde a escola se localiza e os alunos residem. Por intermédio da proposta instigaremos a investigação e curiosidade a respeito da história dos patrimônios históricos e a contribuição dos sujeitos que são homenageados através da representação de seus nomes nos patrimônios públicos e culturais da cidade. 
A aplicação deste projeto possibilitará identificar, analisar e compreender os significados de diferentes objetos, lugares, circunstâncias, temporalidades, movimentos de pessoas, coisas e saberes. Por fim, as avaliações propostas ao final de cada atividade do projeto, representam importantes componentes do procedimento pedagógico do professor e relevante instrumento de acompanhamento da aprendizagem do aluno.

Neste projeto podem ser avaliados o compartilhamento das experiências pessoais dos alunos com relação a história do município e dos sujeitos históricos que fazem parte dessa história, através das suas ações sociais. Além disso, pode ser solicitada uma escrita reflexiva e crítica dos alunos sobre o conhecimento que eles tinham antes da intervenção didática e o adquirido depois do projeto cineclubismo na história local.

As produções escritas são importantes porque:

[...] textos, são formas de representar e encobrir o mundo. Servem para descrever as coisas e lhes dar sentido, suprimindo e integrando, desdobrando e restringindo a realidade ao mesmo tempo. O cinema, como artefato cultural que é, pode e deve ser explorado como forma de discurso que contribui para a construção de significados sociais (PIRES; SILVA, 2014, v. 35, p.1).

Vale reforçar, que a avaliação não se detém somente aos detalhes da apreensão do conhecimento, ela pode servir de suporte de intervenção para o educador, ajudando-o a criar novas estratégias que possam garantir que os discentes obtenham um desempenho promissor e significativo, guiando-o até a linha de chegada do objetivo almejado. Além disso, possibilita o docente refletir sobre os pontos fortes e frágeis da metodologia por ele utilizada, desse modo poderá se superar e inovar na sua didática, atendendo amplamente a demanda do ensino e aprendizagem no que concerne ao desenvolvimento educativo individual e coletivo dos educandos. Dessa forma,

\footnotetext{
A avaliação é, pois, imprescindível à aprendizagem, porque aponta para revisão de programas, propõe novas indagações, mostra incompletudes e indica novos caminhos. Deve estar presente ao longo do processo, não podendo reduzir-se a um momento final de uma prática (GRILLO, 2003, p.18).
}

A avaliação requer atenção minuciosa, não podemos nos ater apenas no sentido classificatório, mas devemos perceber o desenvolvimento de maneira abrangente, em razão das competências e habilidades que o educando no seu ritmo individual, pode desenvolver 
e potencializar gradualmente, os resultados podem não ser externalizados rapidamente, mas no conjunto das observações cotidianas estarão mais aparentes.

A utilização do cineclubismo como recurso pedagógico em sala de aula deve ser avaliado a partir de uma concepção de eficiência obtida durante o andamento da prática do projeto, ou seja, o professor pode avaliar a proposta de utilização do cineclubismo ao longo de sua aplicação em sala de aula, percebendo os pontos positivos e negativos da prática, de formaa refletir sobre o impacto do uso do cineclubismo nas discussões sobre a história local.

\section{CONSIDERAÇÕES FINAIS}

A implantação de um projeto pela perspectiva do cineclubismo na disciplina história tem muito a contribuir para o processo educacional e para trazer o educando para o centro da aprendizagem, além de resgatar a valorização da cultura cinematográfica. Propiciando levar para sala de aula uma nova forma de dialogar com as atribuições benéficas do audiovisual, mediando os saberes, conhecimentos e aprendizados da história do município de Maranguape/CE, que podem ser fortalecidos com a execução do cronograma do projeto proposto.

O projeto abrange durante toda a sua proposta de efetivação pedagógica do desenvolvimento e aprendizagem do sujeito, evidenciando ao longo da teoria vigente neste projeto que a aprendizagem começa desde o início da vida, desencadeada a partir de um processo de apropriação cultural, sendo atingido pelos significados culturais que o circundam.Tal comportamento já é transcendente da natureza humana possibilitando a construção de linguagem, consciência e atividade, passando por uma grande transição, na qual o indivíduo deixa de ser biológico para tornar-se sujeito sócio-histórico.

Percebe-se a existência da complexidade da formação humana, comumente designada no processo do desenvolvimento fundado nas relações gerenciadas pela carga energética das experiências difundida na história individual e social, resultando na imprescindível interação dual entre os seres humanos e seu movimento sociocultural. 
Havendo um diagnostico macroscópico da dinâmica recorrente de ambos os lados, onde no momento em que o homem interfere no meio para suprir suas necessidades, também acaba sofrendo uma ação ativa na relação interpessoal e intrapessoal. Tal assertiva pontua a cultura como um componente da construção humana, dada sua atuação na operacionalização das informações e internalização comportamental humanística.

\section{Referências}

BRASIL. Base Nacional Comum Curricular: Educação Infantil e Ensino Fundamental. Brasília: MEC/Secretaria de Educação Básica, 2017.

BRASIL. Parâmetros Curriculares Nacionais. Brasília: MEC/Secretaria de Educação Fundamental, 1997.

EDUCERE XVII CONGRESSO NACIONAL DE EDUCAÇÃO, XVII., 2015, PARANÁ. FORMAÇÃO DE PROFESSORES, COMPLEXIDADE E TRABALHO DOCENTE [...]. PARANÁ: [s. n.], 2015. 16 p. Tema: A IMPORTÂNCIA DO CINEMA POR MEIO DO CINECLUBE NA ESCOLA. Disponível em:

https://educere.bruc.com.br/arquivo/pdf2015/17809 7889.pdf. Acesso em: 4 jun. 2021.

GRILLO, M. Por que falar ainda em avaliação. In: ENRICONE, D.; GRILLO, M. (Org.). Avaliação: uma discussão em aberto. Porto Alegre: EDIPUCRS, 2003.

LUCCI, Marcos Antonio. A proposta de Vygotsky: A psicologia sócio-histórica. Revista de curriculum y formación del professorado, 2006. Disponível em: ppppp (ugr.es). Acesso em:18 de abril de 2020.

MINAYO, Maria Cecília de Souza. O desafio da pesquisa social. In: MINAYO, Maria Cecíliade Souza (Org.); DESLANDES, Suely Ferreira; GOMES, Romeu. Pesquisa Social: teoria, método e criatividade. 34. ed. Petrópolis: Vozes, 2015. Cap. 1, p. 9-29.

PIRES, Maria da Conceição; SILVA, Sergio Luiz Pereira. O cinema, a educação e a construção de um imaginário social contemporâneo. Educação \& Sociedade, Campinas, v.35, ed. 27, p. 1-10, 2014. Disponível em: v35n127a15.pdf (scielo.br). Acesso em: 22 maio 2020.

PREFEITURA MUNICIPAL DE MARANGUAPE. Secretaria de Educação. Plano Municipal da Educação, Maranguape, 2015.

REGO, Tereza Cristina. Vygostsky: Uma perspectiva histórico-cultural da educação. 1. ed. Rio de Janeiro: Vozes, 1994. 131 p. v. 1. ISBN 85.326.1345-4. 
ROCHA, Helenice Ap.; CAIMI, Flavia Eloisa. A(s) história(s) contada(s) no livro didático hoje: entre o nacional e o mundial. Rev. Bras. Hist., São Paulo, v. 34, n. 68, p. 125-147, dez. 2014. Disponível em

$<$ http://www.scielo.br/scielo.php?script=sci_arttext\&pid=S0102-

01882014000200007\&lng=pt\&nrm=iso > . acessos em 19 maio 2021.

https://doi.org/10.1590/S0102-01882014000200007.

Roiz, D. da S. (2012). < b > História \& Ensino de História </b\&gt;. Revista Brasileira De História Da Educação, 6(2 [12]), 193-196. Recuperado de https://periodicos.uem.br/ojs/index.php/rbhe/article/view/38631

SANTOS, Yasmin. Cineclubismo e Educação: possibilidades do cinema no contexto escolar. Educação, São Paulo, v. 1, ed. 1, p. 1-10, 2020.

$\overline{\text { Trabalho oriundo do I Seminário do GPOSSHE - Educação do campo e Pedagogia histórico-crítica em }}$ contexto de crise e pandemia. 